\title{
DIGITIZATION OF EMBOSSED NUMBERS ON CONTINUOUS STEEL CASTING BILLETS
}

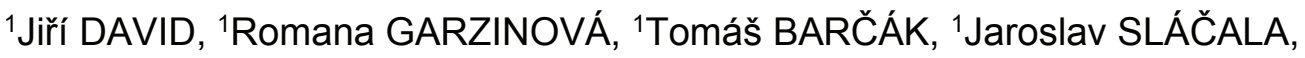 \\ ${ }^{2}$ Nadezhda SHMELEVA \\ ${ }^{1}$ VSB - Technical University of Ostrava, Ostrava, Czech Republic, EU, j.david@vsb.cz \\ ${ }^{2}$ National University of Science and Technology "MISiS", Institute of Economics and Industrial Management, \\ Moscow, Russian Federation, nshmeleva@misis.ru
}

https://doi.org/10.37904/metal.2019.983

\begin{abstract}
Computer Vision is currently one of the most advanced and fastest growing areas of computing and software development. It can be used to recognize objects from the captured image. It is a visual image and video recognition system coupled with artificial intelligence. Industrial vision using industrial cameras is currently used in many industrial areas. Initial capital investment into the vision system has fast economic return, depending on the cost of the system, the number of human operators replaced, production capacity and other parameters. In the case of a properly designed and configured system that can often fully eliminate the human factor. Typical tasks in machine vision can be recognition and counting of products using industrial cameras, positioning, dimensioning, or optical quality control.

The paper will describe the use of machine vision in the metallurgical industry - specifically for the numerical identification of embossed numbers on continuous steel casting billets. The basic requirement of the operation was to create a system for billet identification and archiving of collected data in order to eliminate inaccurate control causing billets to be replaced of each other and fatal manufacturing defects with considerable financial losses. The solution uses a combination of machine vision and neural networks. Combined with automation, advanced data analytics and production management systems, it creates a unique concept of smart metallurgical operation.
\end{abstract}

Keywords: Metallurgy, machine vision, neural networks, control, applications

\section{INTRODUCTION}

In today's industrial companies and manufacturing companies, there is a growing emphasis on product quality and, with this in mind, the number of checkpoints at each stage of production. Checks can be performed manually or automated, or combined. With increasing business modernization and the development of automation technology, many operations are switching to an automated way of control. In view of this, different quality control methods are applied at checkpoints, such as machine vision, surface sensing, accurate shape, color and size measurements or inspection of blanks and product identifiers during manufacture and storage. Many of these control methods utilize an industrial camera as an essential element to deliver the desired information in pictorial form. The aim of this paper is to describe a method of testing optical character recognition using artificial neural networks. Recognition method is the basic algorithm for automatic billet identification system and to eliminate any confusion in their further processing. The introduction should provide a clear statement of the study, the relevant literature on the study subject and the proposed approach or solution.

\section{MACHINE VISION}

Computer vision is one of the most advanced areas of computing. It is used to recognize the required information from an image captured by an industrial camera. Computer vision is widely used, especially in the industrial sector, where it is referred to as machine vision [1]. 
Basically, computer vision with technical means replaces human capabilities in terms of image understanding and interpretation. Typical tasks in machine vision can be recognition and counting of products using industrial cameras, positioning, dimensioning, or optical quality control. In conjunction with other product handling systems, some manufacturing operations can be fully automated with machine vision systems.

The basis for a reliable machine vision system is the appropriate illumination of the scanned scene in which the scanned objects are located. [5] The image data obtained by the scanning device, such as a digital industrial camera, is then processed by the system to recognize the desired information. The system is connected to other control parts of the production line as needed, with which it communicates and can autonomously interfere with the production process or provide signalizing to the operator. Among the automated interventions we can consider stopping the machine, discarding defective and poor quality products, parts rotating in unsuitable positions, etc. Access to the system can also be enabled remotely via an application or web interface.[9]

\section{THE USE OF NEURAL NETWORKS FOR MACHINE VISION}

An artificial neural network can be used to recognize the attached patterns from the image. It serves as a classifier based on associative memory. Images of the submitted patterns are remembered in the net weights and the pattern attached is the answer to the attached pattern.[1] The network layout is solved according to the neural network topology and the number of outputs. One input layer neuron corresponds to one image pixel. The neural network works in two basic phases [7]:

- Learning phase: a) adjusting weights according to input patterns; b) repeating the learning process

- Triggering phase: a) placing an unknown pattern on the input; b) initializing the state; $c$ ) iteration until the answer is found.

For pattern recognition from an image, a series of different types of neural networks can be used, for example: Hopfield network, Kohonen's self-organizing network, or multilayer perceptron neural networks that are used in our solution. etc. [10].

\subsection{Digit Image Classification}

The numeral shape is described by a binary image, each pixel corresponding to one neural network input. Therefore, the input layer is equal to the image resolution (Figure 1).

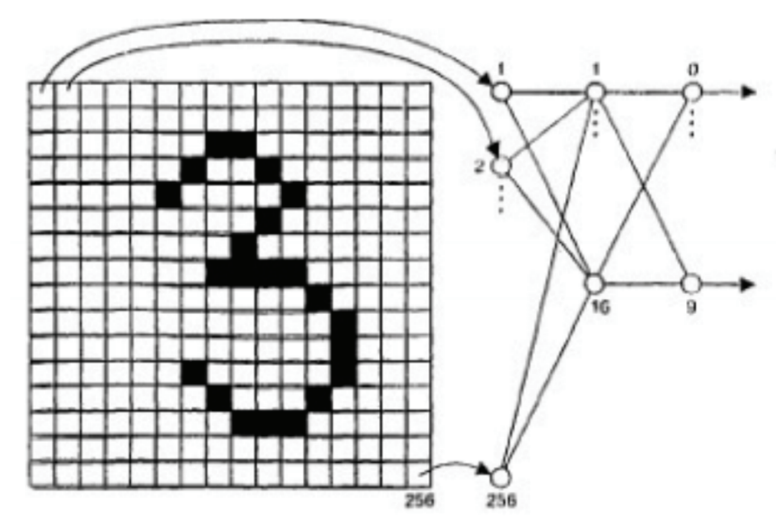

Figure 1 Transforming a pattern with a neural network [3]

However, associative memory does not guarantee invariance to scale, rotate, change font, noise, etc. Independence from these phenomena can be achieved by using artificial neural networks approximation classifiers with a suitably selected training set. [2,4] 
The character is represented by a matrix of zeros and ones (Figure 2 left). Each such feature is the ideal case of the actual character image (Figure 2 right).
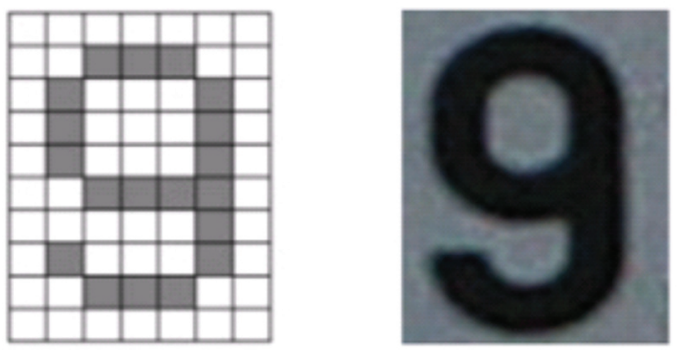

Figure 2 Transforming a pattern [3]

In the character recognition task, the individual lines of the character pattern are arranged one after the other and represent a single line pattern. [2]

\subsection{Automatic identification of embossed numbers on continuous steel casting billets}

The basic semi-finished product for the production of wire rod is steel billets, which are stored in the rolling mill area and further distributed to the production line according to the requirements of the production plan. During this process, the billets are inspected only in the backfill grate areas without control from the operator's station before entering the heating furnace, and in some cases be running out inaccurate check and exchange of billets.[6] Since the material properties of individual billets vary greatly depending on the use for particular products, their exchange results in fatal manufacturing defects and large financial losses.

Input information and operating requirements

1) Steel billets have for identification purposes by a serial number, which is created by an marking automatic machine immediately after the billets exit from the continuous casting machine.

2) The numeric character contains a combination of 5 to 9 digits, possibly accompanied by two letters.

3) The steel billets are arranged on the charging grate and individually conveyed to the heating furnace.

4) For the purpose of billet identification, the possibility of digitizing numerical characters on the computer monitor of the operator's station and the possibility of archiving the obtained information is required.

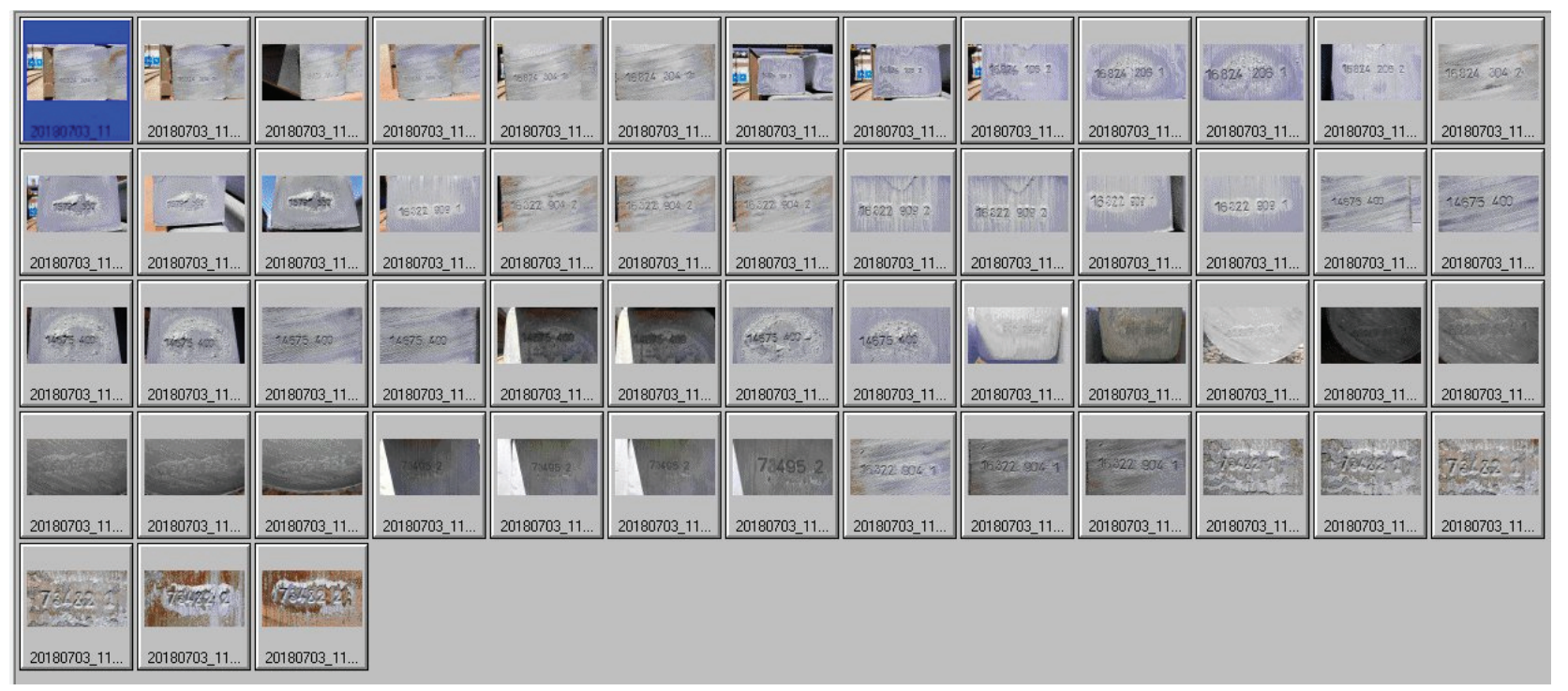

Figure 3 Operational shots with embossed numbers on continuous steel casting billets 


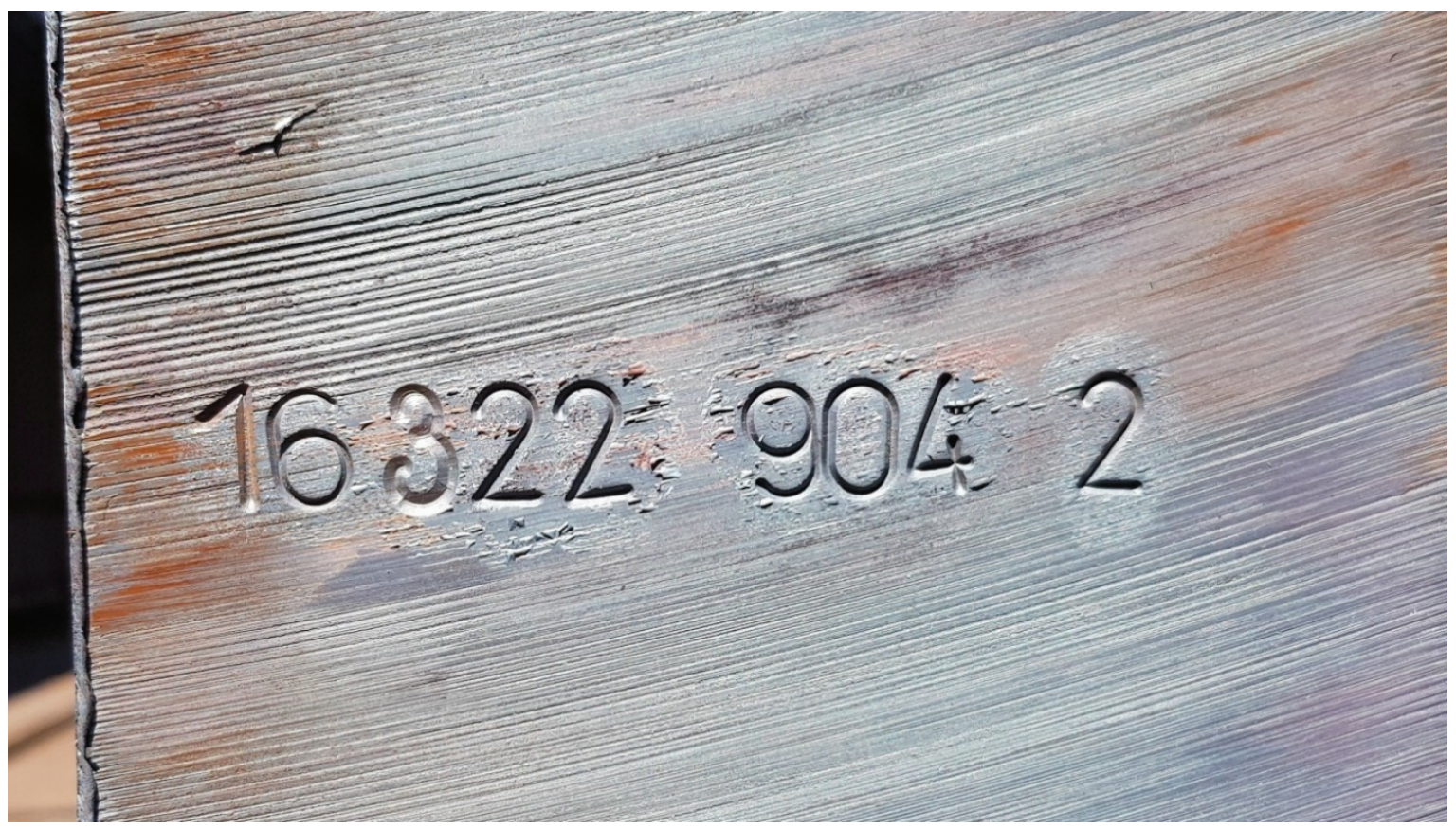

Figure 4 The numeric characters on the billet faces

To create the method, a series of 45 images in original, black and white and negative colors with numeric characters on the billet faces shown in Figure $\mathbf{3}$ were used. Figure $\mathbf{4}$ is a detail of the face of billet with embossed numbers.

Numerical patterns (Figure 5) are separated from the images, which form the basis of the training set for learning the neural network.[8] The neural network was created in STATISTICA. Figure 6 shows screen the software STATISTICA with visualization of selected neural networks that have been tested.

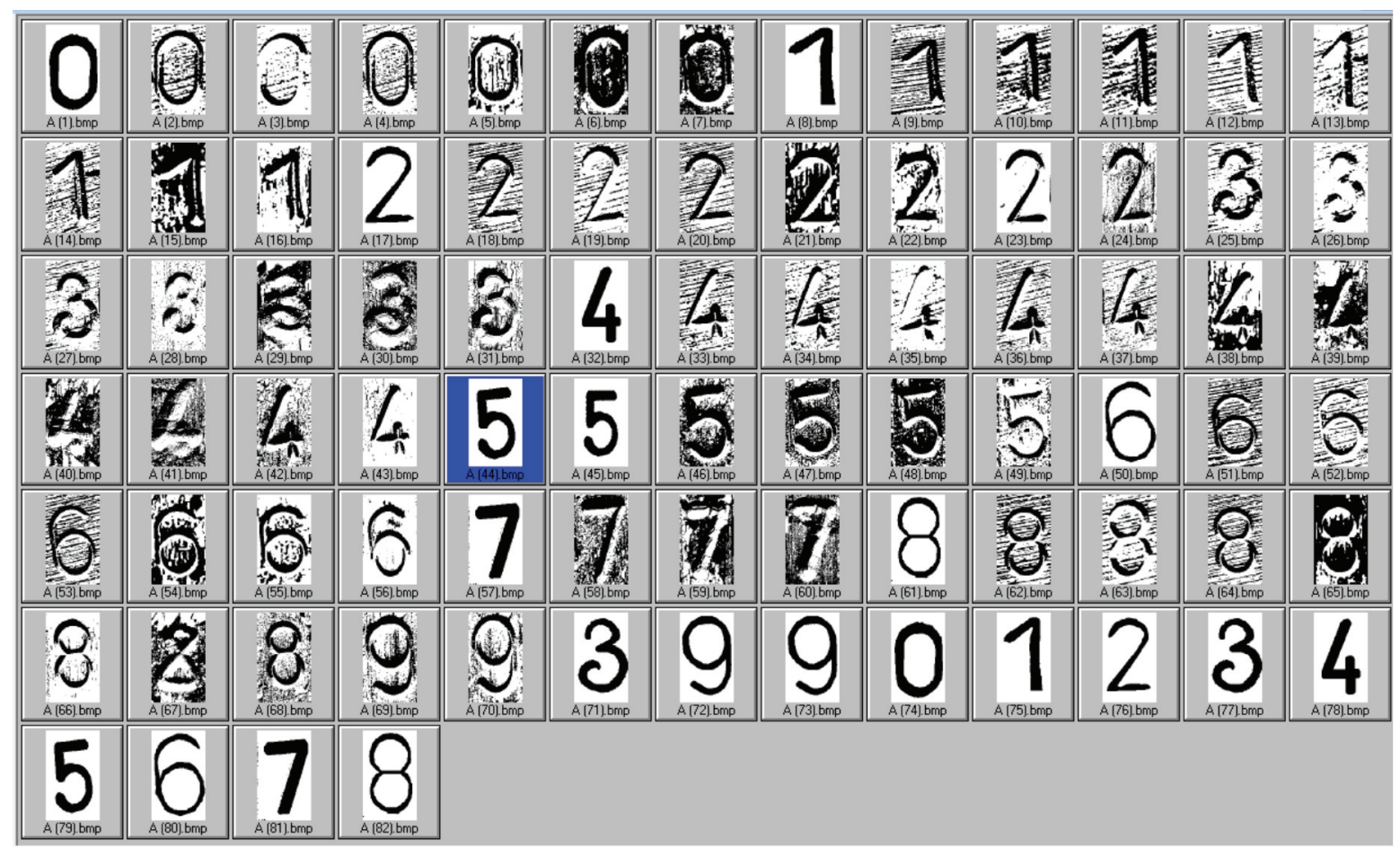

Figure 5 The images, which form the basis of the training set 


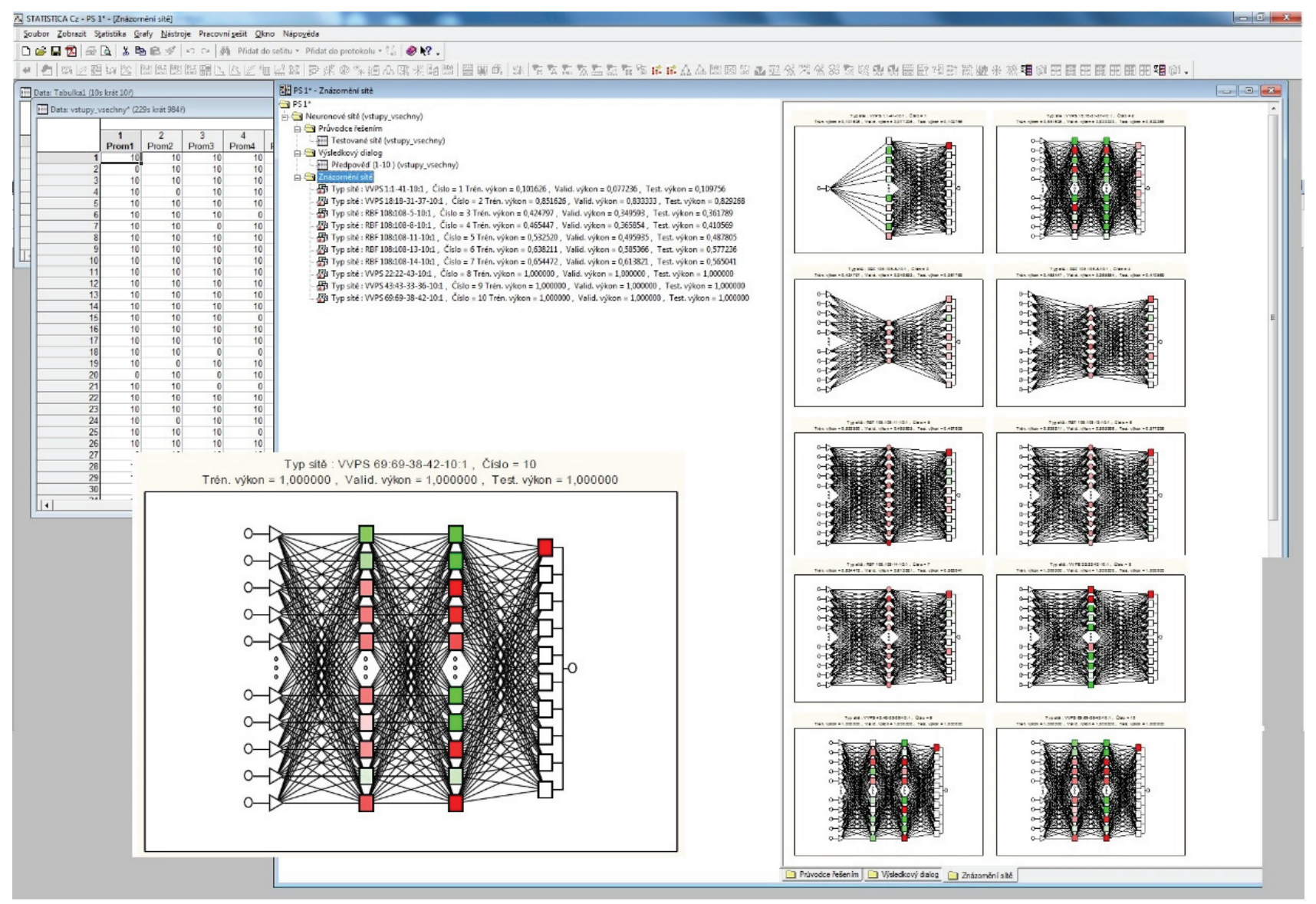

Figure 6 Screen the software STATISTICA with visualization of selected neural networks

The result of the solution is to find a multilayer percepron's neural network with VVPS 69-38-42-10 topology. The resulting neural network is transformed into $C$ \# programming code and is the foundation of the emerging industrial application.
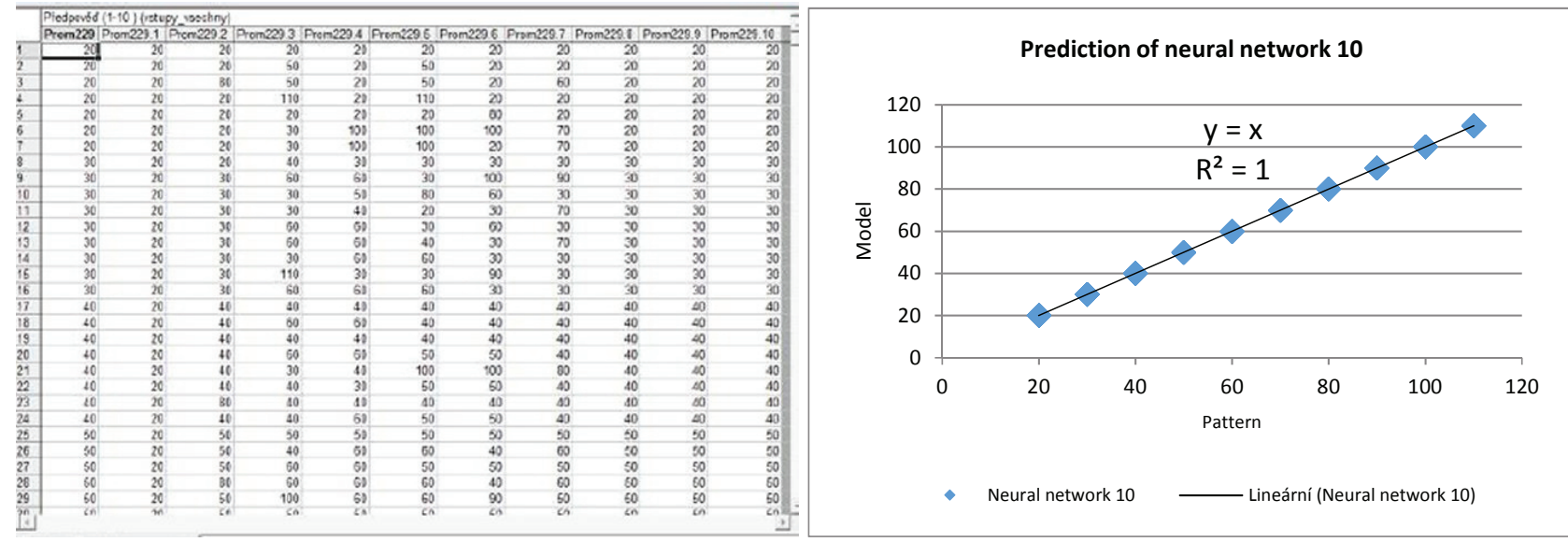

Figure 7 Predictions of the tested network 10

Figure 7 in left shows the predictions of the tested networks and in right the prediction graph of the resulting neural network with $100 \%$ classification of embossed numbers. 


\section{CONCLUSION}

The paper presents a part of the machine vision system for automatic identification of embossed numbers of continuous castings on rolling mills. The creation of this system was initiated on the basis of the real requirements of the operation, because of higher automation of operation and ensuring the control on continuous steel casting billets according to the production plan. The machine vision system will use the camera to scan the space in front of the heating furnace and allow automatic checking of the identification numbers on continuous steel casting billets. The output of the system will be digital information of numeric characters on the computer monitor of the operator's station and the possibility of archiving the obtained information.

Artificial neural networks were used for automatic identification of embossed numbers. The application of artificial neural networks in the field of image processing is not new, but the uniqueness of the proposed solution lies in the modification of this processing, which results in significant simplification. The proposed and implemented algorithm for automatic identification of embossed numbers does not suppress background noise, thus does not perform pre-processing and segmentation, thus greatly simplifying the solution and accelerating the final processing while maintaining $100 \%$ classification of embossed numbers. The whole solution was done on real images.

\section{ACKNOWLEDGEMENTS}

The work was supported by the specific university research of Ministry of Education, Youth and Sports of the Czech Republic No. SP2019/17, SP2019/62 and RPP 2019/27.

\section{REFERENCES}

[1] ŠONKA, Milan, HLAVÁČ Václav and BOYLE Roger. Image processing, Analysis, and Machine Vision. 3rd ed. Toronto: Thomson, 2008. p. 829.

[2] HORÁK, Karel, KALOVÁ, llona, PETYOVSKÝ, Petr and RICHTER, Miloslav. Počitačové vidění. 1st ed, Brno: VYSOKÉ UČENÍ TECHNICKÉ V BRNĚ, 2008. p. 132.

[3] BOVIK, Al. Handbook of Image and Video Processing. 2nd ed. London: Academic Press, 2000, p. 891.

[4] SEIDL, David., KOŠTIAL, Pavol., JANČíKOVÁ, Zora., RUŽIAK, Ivan., RUSNÁKOVÁ, Soňa and FARKAŠOVÁ, Martina. Modal analysis - Measurements versus FEM and artificial neural networks simulation. Communications in Computer and Information Science, 2011, vol. 188 CCIS, Issue PART 1, pp. 170-175.

[5] SZELISKI, Richard. Computer Vision: Algorithms and Applications. 2011 ed. New York: Springer Publishing, 2011. p. 812.

[6] DAVID, Jiří., ŠVEC, Pavel and FRISCHER, Robert. Support for maintenance and technology control on slab device of continuous casting. In: METAL 2013: 22nd INTERNATIONAL CONFERENCE ON METALLURGY AND MATERIALS. Ostrava: TANGER, 2013, pp. 1650-1655.

[7] PUJARI, Pradeep, KARIM, Md. Rezaul and SEWAK Mohit. Practical Convolutional Neural Networks. 2nd ed. Birmingham: Packt Publishing - ebooks Account, 2018. p. 218.

[8] JANČíKOVÁ, Zora, KOŠTIAL, Pavol, BAKOŠOVÁ, Dana, SEIDL, David, DAVID, Jiří, VALíČEK, Jan and HARNIČÁROVÁ, Marie. Neural Model for Prediction of Tires Eigenfrequencies. Advanced Structured Materials. 2013, vol. 41, no. 1, p. 1-11.

[9] FORSYTH, David A. and PONCE, Jean Computer Vision: A Modern Approach. 2nd ed. London: Pearson, 2011. p. 800.

[10] KANDEL, Eric R. Principles of Neural Science. 5th ed. New York:McGraw-Hill, 2012. p. 1504. 